\title{
Zobo Tea Package Design Prototype Allied with Product Onomastics
}

\author{
Ayorinde S. Oluyemi (i) \\ Department of Fine and Applied Arts, Nnamdi Azikiwe University Awka, Nigeria \\ E. Bankole Oladumiye (i) \\ Department of Industrial Design, Federal University of Technology Akure, Nigeria \\ Oluwafemi S. Adelabu \\ Department of Industrial Design, Federal University of Technology Akure, Nigeria
}

\begin{abstract}
Received: November 18th 2021, Revised: December 17th 2021, Accepted: December 20th 2021
Refer: Oluyemi, A.S., Oladumiye, E. B., Adelabu, O. S., (2021), Zobo Tea Package Design Prototype Allied with Product Onomastics, Journal of Design Studio, V.3, N.2, pp 237-259,

A.S. Oluyemi ORCID: 0000-0002-2743-2992, E. B. Oladumiye ORCID: 0000-0002-0001-546X, O.S. Adelabu ORCID: 0000-0002-10804083

DOI: $10.46474 /$ jds.1025264 https://doi.org/10.46474/jds.1025264
\end{abstract}

\begin{abstract}
The purpose of this design is to create a Zobo tea package design prototype allied with African indigenous onomastics. African indigenous products are effective in terms of functionality; however, industrialized products gained more attention because of aesthetics, safety, hygiene, and other advanced technology put into consideration during production. This seems to boost the inferiority of indigenous products. Hence, the present study focuses on indigenous Zobo tea in terms of creating a conceptual package design prototype enhanced with product onomastics. Twenty-two names are derived for indigenous Zobo tea by making use of linguistics techniques. These names are used as label for designing a conceptual package prototype for indigenous Zobo tea. A Delphi technique is adopted for the evaluation of this creative process. The findings show that homonym as an onomastics will enhance the branding and development of indigenous Zobo tea even in the international market. This will remodel the inferiority of the aesthetics of Zobo indigenous products. Hence, research on the choice of an appropriate name for a particular product should be a contemporary research area to improve the present situation of our indigenous product branding and graphic design. It is believed that the outcome of this research could provide guidelines for effective naming in product package design for indigenous product development; as creative designers must not only understand the vocabulary of graphic design but be aware of extraneous constraints that could affect their designs.
\end{abstract}

Keywords: Branding, Package Design, Product Onomastics, Prototyping Zobo Tea

\section{Introduction}

Conceptual prototyping is the creation of simple, incomplete models or mockup of a design for the purpose of exploring preliminary design ideas quickly and inexpensively (Collins Dictionary, 2012). This study explores product onomastics to elucidate one of the uncommon areas that graphic designers could be creative thinkers and expert communicators (Abushawali, Lim \& Bedu, 2013). According to Abushawali, Lim, and
Bedu, designers referred to themselves with more comprehensive designations such as 'Visual Communicator, Visual Designer, Graphic Communicator, and Communication Specialist in the international business world (Abushawali et al, 2013). Kirk thus opined, "If, given the opportunity to make a suggestion, all designers should know the general guidelines to product naming" (Kirk, 2013). Hence, present study suggests conceptual package design prototype allied with Zobo tea 
indigenous onomastics. Onomastics entails the study of names and naming systems. It is derived from the Greek word 'onoma' meaning 'name'. The idea of product onomastics is to create code of latent meanings for the product that the consumers can grasp either consciously or unconsciously (Marcel, 2013). Hence, this study is proposed as an attempt to build on the existing body of knowledge concerning onomastics (naming system) of Zobo tea and particularly focusing on the conceptual prototype by making use of Computer-Aided Design (CAD) software. Computer Aided Design can be seen as means of simulating a real environment of a design. It is believed that the outcome of this research could provide guidelines for effective naming in product package design for indigenous product development; as creative designers must not only understand the vocabulary of Graphic Design but be aware of extraneous constraints that could cause cognitive dissonance in their design.

\section{Derivation of Product Onomastics as Regards Zobo Tea Package Design Conceptual Prototype}

Sometimes, computer applications are used for name derivation; however, Lertcheva, Malik, and other prior researches explain the different derivational processes for forming brand names (Lertcheva, \& Aroonmanakun, 2011 and Malik, 2015). Among these processes are alliteration (example is Coca-Cola), assonance (example is EvocaCola), consonance (example is Happy Hour), rhythm (example is Better Business Bureau), clipping (example is FedEx), blending (example is malt + tonic $=$ maltonic), onomatopoeias (example is Pop), removal techniques (example is Natural $-1=$ Natura), replacement technique (Example is Origin = Orijin), homophone technique (example is Active =Activa), suffice technique (example is power + ade $=$ Powerade), prefix technique (example is Nutri + milk $=$ Nutri milk). It is also discovered that the tradomedical practitioners in Nigeria make use of several morphological processes in naming their products and the commonest morphological process used is blending (Ogunsote, Prucnal-Ogunsote \& Umaru,
2006). Accordingly, this research focuses on the onomastics (naming system) of Zobo tea and particularly focusing on the conceptual prototype by making use of Computer-Aided Design (CAD) software.

Considering Najmuldeen (2021) point of view about traditional graphic designers, present study adopts CAD software for conceptual prototyping instead of sketching on paper or by creating 3D model with cardboards. Despite digital divide affecting graphic design as identified by Najmuldeen (2021) present study adopts both 3D and 2D software namely Autodesk 123D Design and CorelDraw. According to Najmuldeen (2021) many traditional graphic designers are finding it difficult to adapt to the drastic change of using CAD. He predicted that young generation may face similar challenges in future because of the changing technology. Hence, present study adopt Autodesk 123D Design because it is an open source software and it is elementary in techniques. The interface is not complex and very easy to interact with. It is available in both 32 bit and 64 bit, as well as online and offline platform. Present study is of the notion that one CAD software may not be able to perform all design tasks, hence two or more can be used (for instance, this study uses Autodesk 123D Design, Adobe Photoshop and CorelDraw. Recently, there is news that Autodesk no longer support 123D Design. Alternative CAD software includes AutoCAD, Sketch up, Solid Edge, SOLIDWORKS, and to mention a few. There is need to have research paper that documents CAD software such as Autodesk 123D Design. Hence, this paper fills this gap by using it for a conceptual prototyping because of its user-friendliness and commonness. A beginner can easily get the technicality needed for creating carton for a product by using Autodesk 123D Design. Notably, the form of a cube is readily available in a $3 \mathrm{D}$ CAD software. 


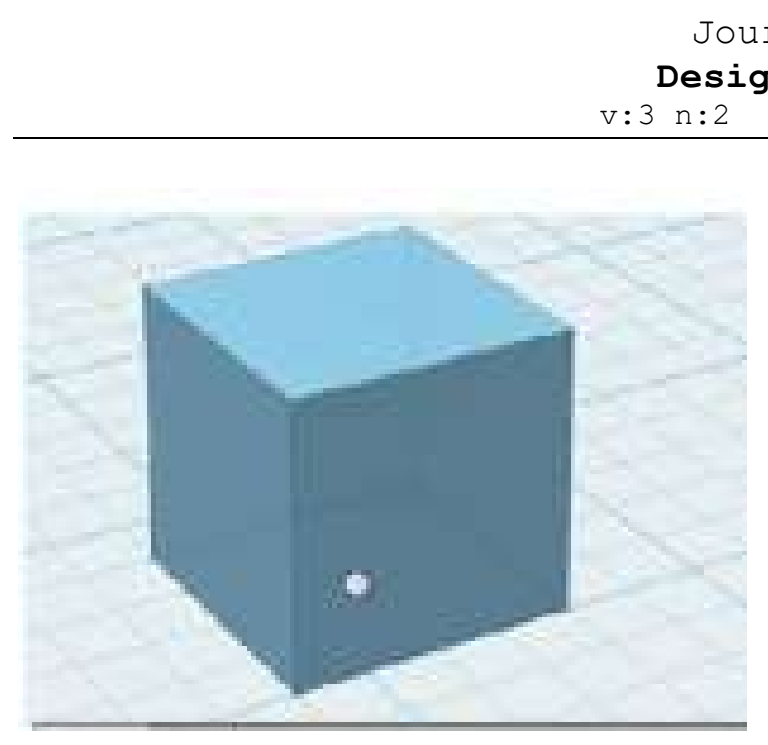

Figure 1: A cube readily available in Autodesk $123 D$ Design software.

As glimpsed in Figure 1, the creation of a carton can be easy for someone new to $3 \mathrm{D}$ modelling. It is simply by using the primitives at the tool bar. These primitives can be edited to the desired dimension and form. Package in form of a carton is just a cube or box. There is no stress in using cube primitive for the carton. In the study of Oladumiye, Oluyemi, \& Adelabu (2018) on percentage distribution of form in respect of a typical tea package design, carton has been calculated to be the predominate above other forms like cup, bottle, pouch, tub, tin/can, Tetra Pak package system and to mention a few. Out of $7.8 \%$ of the identified package form for a typical tea, $6.5 \%$ are packed in carton while other package forms are below $6.5 \%$. Hence, present study considers carton as the package form for a Zobo tea.
Also, prior researches have examined various measures for choosing an appropriate name for products. These researches itemize the criteria for good naming of products. Table 1 shows the criteria as elucidated by Chan and Huang (Chan, \& Huang, 1997).

Product onomastics should suggest product benefits either consciously or unconsciously. This will promote the product brand in both product display and advertisement. Graphically, it should match the package design aesthetically. All aforementioned are the marketing criteria as put in to consideration by Chan and Huang (Chan, et al, 1997). Other criteria are the legal and linguistics aspect as itemized in Table 1. The notion of present study based on Chan and Huang's prescription is that Zobo tea onomastics either in generic or trademark form should follow marketing, legal and linguistics criteria as itemized in Table 1. Other marketing features includes its suitability with the product image and package form. This requires the graphic design expertise in collaboration with consumers' research. The consumers' mind needs to be understood by the designer. This also creates room for conceptual prototyping. This is one of the gaps present exploratory study fills by adopting the concept of using package form typical for a tea purposively for easy recognition or identification. This will remodel the inferiority of the aesthetics of Zobo indigenous products.

Table 1: Measure for a good name (adapted from Chan and Huang, 1997, p. 228)

\begin{tabular}{lll}
\hline Marketing & Legal & Linguistics \\
\hline Suggestive of product benefit & Unique & Easy to pronounce \\
\hline Promotable & Pleasing sound \\
\hline Advertisable & Easy to read \\
\hline Persuasive & short and simple \\
\hline Suited To Package & Positive without negative connotation \\
\hline Fit With Product Image & Contemporary \\
\hline & Memorable \\
\hline
\end{tabular}


The legal aspect is about the trademark ability of the onomastics. A unique name that will not easily become a dictionary word (generic word) should be used. Product onomastics should suggest product benefit as well as capable of persuading the consumers' purchase decision. Indigenous/ cottage/ locally produced Zobo tea, having possessed the good marketing features in the aspect of onomastics will be capable of good patronage in the international market. Stakeholders should understand that they cannot just give any name to their products. Cottage producer of Zobo tea will like to have his or her products to be consumed in the international market if digital divide will not be a barrier. The Zobo tea can be advertised on the internet. This is because ecommerce or e marketing can be adopted. The easy pronunciation, pleasing sound, readability, positive connotation of product name and to mention a few as itemized in Table 1 should be followed as to bring cottage indigenous products to an international market. Hence, present study attempts the harmonization of this criteria in to the African language in an English way by using linguistics word formation. The word length of a product onomastic should be short and simple. This will also help the designer to present the typography aspect in a more graphically appealing way. A product onomastics will be considered contemporary when it looks modern. The study of Blijlevens, Creusen, \& Schoormans (2009) addresses product attributes in the aspect of modernity, simplicity and unity. Zobo tea onomastics can also argument these product attributes when the word length/appearance/ orthography is simple, short, modern, understandable (.i.e. meaningful without negative denotation or connotation) and memorable (i.e. easy to recall or remember.) In a nut shell, present study also stand in the position of interdisciplinary research by attempting to collaborate graphic design with language studies, though in an elementary way.

\subsection{Application of Computer Aided Design (CAD) Software for Graphic Communication}

Design presentations have been enhanced with the virtual reality features in CAD and designers now have efficient environment to communicate their ideas. This has enabled them to easily interact with software that could help them actualize their various creative ideas. Designs are aided by computers with the medium of a software which is pre-installed in the computer (Ogunsote et al., 2006). In structural design, 2D and 3D Computer Aided Design (CAD) software are used for modelling. Virtual designs can be created or printed out through printing technology. 2D modelling software creates two dimensional designs (i.e. flat designs or designs that will show a simple view); 3D modelling software will present different views of a design. Various angle of the design can be seen with the aid of 3D modelling software. Examples are Cinema 4D, AutoCAD which are 3D CAD software for both animation, rendering and modelling. SOLIDWORKS and CATIA are developed by the same company; while CATIA is based on surface modelling, the inner parts modellings are done with SOILDWORKS. These 3D CAD softwares are popular 3D CAD softwares for developing mechatronics (.i.e.an integration of various engineering including robotics, electronics, computer science, and to mention a few) system from beginning to the end. Lumion is a visualization software for a rendering madeeasy for architects. There is need for internet to use this software. Sketchup also uses internet. Someone in country that is negatively affected by digital divide will have the challenge of using this software unless the offline version is made available for them. This exploratory study will use both 2D and 3D modelling software so as to simulate Zobo tea package allied with product onomastics. Rendering software will simulate real scene, texture or environment for the design. It will help to add depth and animation or other real life effects to the design. It will show three dimensional designs (.i.e. design in round and not in flat). Animation software is based on a frame by frame basis. This will enable movement or 
motion graphics to be created.

Vector software will not generate images that will pixelate (i.e. a kind of mosaic or dots that appear especially in enlarged images). Bitmap software can be called raster graphic software. The images generated with raster graphic software do pixelate (.i.e. form tiny dots of the images) especially when enlarged or magnified by using zoom tools. Presentation software have graphic user interface, translation and animation tools which can help a presenter in revealing or narrating their ideas to audience. Publishing software are useful for book design project for both online publication and printed copy of a publication design such as newspaper or magazine and to mention a few. can be that - 'a graphic designer is expected to be versatile in product branding task more than the client'. Whereas, such graphic designer can only use vector graphic software such as CorelDraw. Such a graphic designer can experience what this study attempts to document on conceptual Zobo tea package design prototype allied with product onomastics. This study is of the notion that Najmuldeen (2021) observation is correct because digital divide would affect a designer in an old economy country. Old economy country will affect the knowledge growth of a particular group. It is not a surprise that a designer in an old economy cannot use any of the 3D CAD software itemized in Table 2.

Table 2: Shows some examples of CAD software

\begin{tabular}{ll}
\hline Category & Examples of Software \\
\hline 2D \& 3D modelling software & $\begin{array}{l}\text { 123 D Design, Cinema 4D, AutoCAD, SolidWorks, Autodesk Revit } \\
\text { Building, ArchiCAD, TurboCAD, SketchUP, Lumion }\end{array}$ \\
\hline Rendering Software & 3D Studio Max, Cinema4D, ArchiCAD, AutoCAD, Form-Z, TurboCAD, \\
& CATIA \\
\hline Animation software & 3D Studio Max, Blender, Bryce, Flash, Ray Dream Studio, SoftImage, \\
& True Space, Maya \\
\hline Vector software & CorelDraw, Adobe Illustrator \\
\hline Bitmap software & Adobe PhotoShop, Microsoft Paint, Corel Photo Paint, MicroGrafx Pic \\
\hline Presentation software & Microsoft PowerPoint, Harvard Graphics \\
\hline Publishing software & Adobe PageMaker, Microsoft Publisher
\end{tabular}

For a design task, designer can decide to use one software or more. It depends on the level of proficiency of such designer. Present study does not prove its level of expertise in using Autodesk 123 D Design but it attempts a service training approach. This is a simulation of the experience an average graphic designer can face in the contemporary design in order to meet the needs of their clients. Clients have a very high expectation from a graphic designer. For instance, a client may believe that a particular graphic designer should be able to use Cinema4D or solid work for product development. Such a client may also expect the designer to create a unique brand name for the product as well. The belief of such a client
In the African continent, a designer who does not have access to good computer system and internet service have been affected by digital divide. Present study fills the gap of documenting the possibility of using open source and elementary software for conceptual prototyping for designers that are not affected or partially affected by digital divide. Digital divide is the setback in the economic growth of particular region lacking digital benefits such as good computer systems and to mention a few. By using reflection techniques, CAD software itemized in Table 2 can be classified in to two; namely, those that are less affected by digital divide and those that are more affected by digital divide. CorelDraw, Adobe 
Photoshop and Microsoft power point will belong to the group that is less affected by digital divide because they are popular in the location where this study have been carried out. A designer in Nigeria may be proficient in using CorelDraw and Adobe Photoshop compare to Maya, 3D studio Max and to mention a few because of digital divide. Notably, AutoCAD is popular among structure designers such as builders, architect, and engineers. By reflection or intuition, there are avid learners among Nigerian graphic designers that are ready to be expert in using almost every CAD software but digital divide handicapped them. However, the influence of digital divide on designers is not the focus of this study. Autodesk 123 D Design, Adobe Photoshop and CorelDraw are suitable for exploring preliminary design ideas quickly and inexpensively in African, specifically Nigeria. So, 2D and 3D modelling software including vector and bitmap software are considered for the conceptual prototyping of the Zobo tea package considered in this study. This idea is also time-bound because of the changing economy and technology. In the nearest future, this idea may not be reckoned with. This exploratory study fill the gap of documenting this time-bound idea so as to enable future study to correct its weakness and build on its strengths towards better research outcome in product package design innovation. This will remodel the inferiority of the aesthetics of Zobo tea or another indigenous/cottage/locally produced products. It is believed that the outcome of this research could provide guidelines for effective naming in product package design for indigenous product development; as creative designers must not only understand the vocabulary of Graphic communication but should grasp interdisciplinary terms as well.

\section{Method and Materials}

The idea stage begins with the stage of the discovery of ideas in the form of concept useful as reference for the Zobo tea package design prototype allied with African indigenous onomastics. Concepts can be understood as a strategic rationale for achieving one goal. At this stage the first execution is to make observation and gather information. With the application of $5 \mathrm{~W}+1 \mathrm{H}$ (what, why, who, where, when and how) as the foundation of design thinking, the derivation of product onomastics are brainstormed and studied from prior researches. By using question applied brainstorming, how can linguistics techniques of word formation derive name for Zobo tea? The answer of the question 'how?' will also help to answer the question 'what?' - What are the brand names of Zobo tea representing African Indigenous Onomastics? By limiting the study to the survey consisting of data of the Non-Alcoholic Beverages' package designs collected between October 2016 and June 2018, there are no Zobo branded tea in the Nigerian Shopping Mall, though it was purposively sampled by Oluyemi \& Oladumiye (2020). Based on mere reflection and intuition or observation, Zobo tea are sold as generic products mostly through hawking by children and some women. Biological study by Awe, Fagbemi, Ajibola, \& Badejo (2012) narrated that Zobo is drunk not only in Nigeria but across Africa because of the antioxidant properties (.i.e. ability to prevent cell damage; this is a healthy benefit to the organs such as heart and to mention a few).

Why exploring Zobo tea product package allied with product onomastic? The significance of exploring product onomastics cut across in-service training techniques (.i.e. expanding the scope of ones knowledge in a practice) which designers are liable to face in contemporary design practice. The expectation of cottage business concerning what designers can do in terms of product innovation is not low. This is one of the rationales for collaborating conceptual prototyping with product onomastics. Some clients expect a graphic designer to design product package beyond 'just generic cottage or indigenous (local) product'. Cottage entrepreneur's expectation is that the graphic designer will designate the name for the product as well as create the visual design. These clients expect total package design from the designer. Their expectation is that a designer should be versatile in brand design expertise that will minimize the inferiority of indigenous 
products. Notably, the study on graphic design in visual branding by Kirk (2013) refers to the possibility of designer's encompassing knowledge about product naming. This is one of the gaps this exploratory study fills by adopting the concept of using package form typical for a tea allied with its onomastics purposively for easy recognition or identification. This will remodel the inferiority of the aesthetics of Zobo indigenous products. This will serve as means of documenting this time-bound idea so as to enable future study to correct its weakness and build on its strengths towards better research outcome in product package design innovation. It is expected that in the future, Zobo tea will be in the international market like other non-alcoholic products (such as milk, coffee, and to mention a few that have several thousands of brands) in the world already.

The question 'Who?' is not new in any design process. The target audience or consumers are the crucial consideration of a design. Due to globalization, international consumers are considered. Hence, indigenous product onomastics considered in this exploratory study are not pure dialects but words fashioned in English Language. Lindstrom (2001) identified the relevance of English Language in translating information in a global language. This does not mean that English Language is the global language but one of the most popular languages in the world. In a question asked by a researcher 'What language do you most confident with?'- majority are most confident with English word on packaging design for Taiwanese souvenirs (Yang, 2018). The question 'Where?' does not have ambivalent answer. The world is now a global village; however, there is the challenge of digital divide. This exploratory study, though considered as indigenous African onomastics is considered in a global context by using both English and African words. The question 'When?' seems to have an ambivalent answer because of the trend of innovation in product brand design. As earlier stated this exploratory study also documents a time-bound idea so as to enable future study to correct its weakness and build on its strengths towards better research outcome in product package design innovation. It is expected that in the future, Zobo tea will be in the international market like other non-alcoholic products in the world already. Is it not surprising that the brand 'Cellophane' later become generic after many years of existence? Google become a verb 'google' (i.e. to search the internet). Sometimes, consumers will refer to 'CocaCola' as 'Coke'. Now, the mistake will not be noticed when all soft drinks are called Coke. Having noticed that this happened to great product brands, the development of the indigenous Zobo tea beyond generic brand is necessary. Present study addresses contemporary product onomastics possible for a Zobo tea package design by considering the graphic appeal of the product name. Other features of a product name may become generic except the graphic appeal. By graphic appeal, this study refers to how the name appears appealing when printed on a product package. Below is the explanation for how the study explores product onomastics allied with product package conceptual prototyping.

Data are collected through both primary and secondary sources. Primary sources are obtained in the design studio while making use of 123 D Design, CorelDraw X5 and Adobe Photoshop CS5 to creating conceptual package design prototype for indigenous Zobo Tea. The secondary sources includes dictionary, journals, internet, and other literatures. By using Delphi techniques, the conceptual prototype package design allied with the Zobo tea indigenous onomastics are then displayed to the 5 anonymous participants for evaluation. A visual display (.i.e. monitor) is used as the instrument for showing the conceptual prototype package design allied with the Zobo tea indigenous onomastics. Figure 2 shows the beginning of the Autodesk $123 \mathrm{D}$ Design software for generating the mockup for the indigenous Zobo tea package design. 


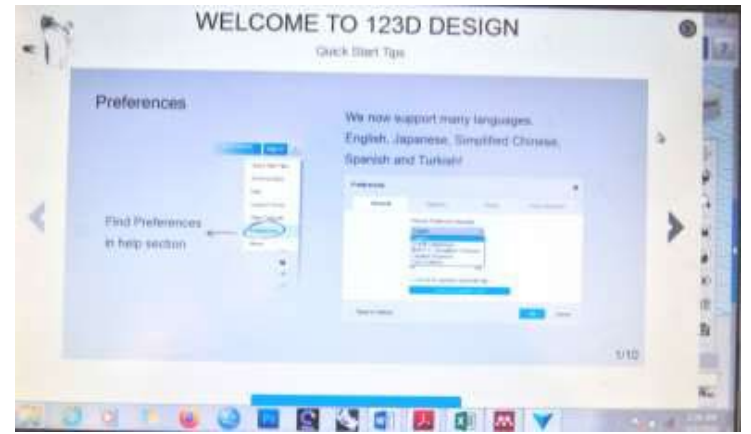

Figure 2: The starting of the 123 D Design software

The graphic interface environment in Figure 2 shows that $123 \mathrm{D}$ Design software has the advantage of Language preference. It is available in many languages (English, Japenese, Chinese, Spanish and Turkish language). To proceed to the next stage the direction of the arrow should be used by just clicking on it. The stage will show the workspace environment where tools can be used for a design project.

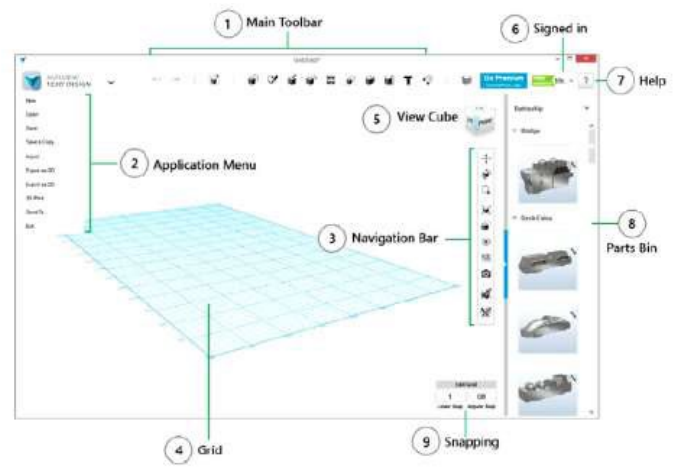

Figure 3: Annotated picture of the features of Autodesk123 D Design graphic interface environment

Figure 3 is the annotated picture of the features of Autodesk123 D Design graphic interface environment. The number one feature is the main toolbar. This consists of the primitives (i.e. building blocks of 3D basic geometric form). These primitives can be edited either by transforming or construction. The number two is the application menu consisting of new, open, save, save a copy, import, export as 3D or export as 2D, import and export files. Directly send the files to different applications or simply send to 3D Printer or to Online Print Service. The number three is the navigation bar which helps movement around the environment of the Autodesk 123 software. The number four is the grid which is the platform on which the model is built. It can be switched off or on by clicking it on the navigation bar. The number five is view cube; this is the easiest way to view different angles or sides of the model. The number six is the sign in, this is to go online. Design in Autodesk 123 software is available in both offline and online. The number seven is the help; this is for learning more about the product. The number 8 is the part bin where already made models are available. The number nine is snapping and is for ensuring precision setting for the model within the grid; it fits the model perfectly in a proper alignment.

Figure 4 shows how the package form for Zobo are generated by creating the carton for the Zobo tea in 3 dimensional solid form. There is no need of using the part bin because already made carton model is not made available probably because the design is done offline. Only the geometric shapes (such as cube and so on can be useful). Other models at the part bin includes numbers, letters, gadget, gear, hardware and lightning fixture.

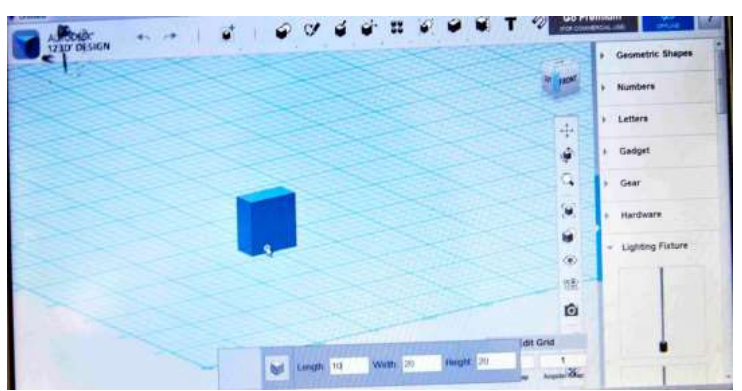

Figure 4: Generating the package form for zobo

By clicking on the cube primitive, the dimension in terms of length, width and height will show. Hence, further editing in terms of modifying the dimension and structure also starts as seen in Figure 5. 


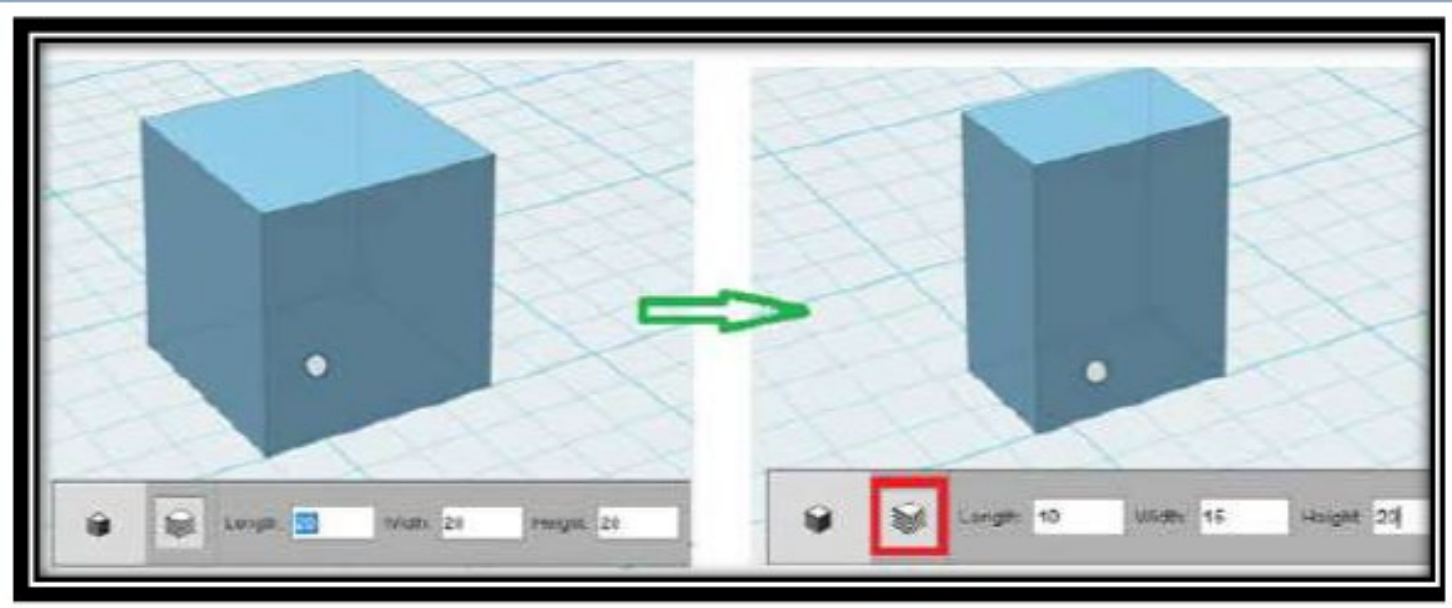

Figure 5: Further editing in terms of dimension

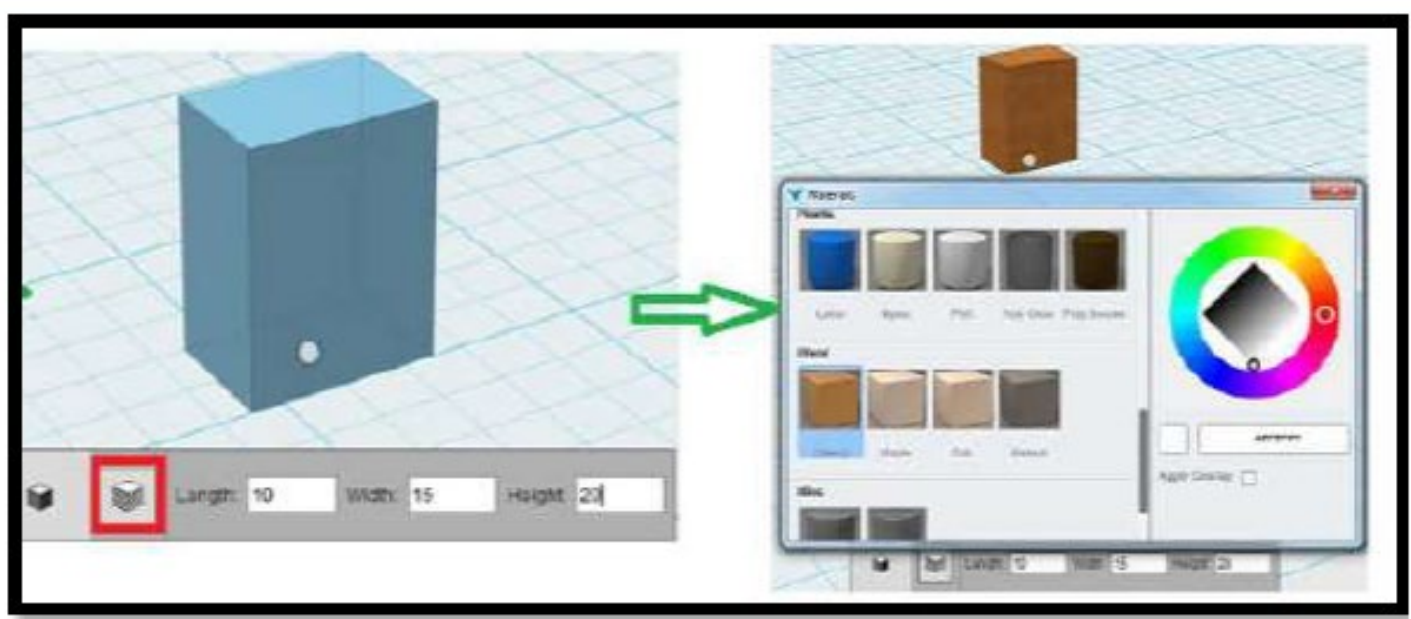

Figure 6: Generating material for the package form

Figure 6 includes the selection of material for the box/carton. The material has to be paper but there is none except wood. Other materials include PVC, nylon, and to mention a few. The next stage is to drag the primitive in to the material. Then, the colour and texture of the box is modified.

Rendering of the model is not adopted. The modified primitive in Figure 7 can be saved as 123Dx format. CorelDraw will not be able to open such files. The model is then captured by using snipping tool in the windows operating system. This is then opened in CorelDraw for further design. Figure 8 shows the snap shot of the generated package form saved for further design.

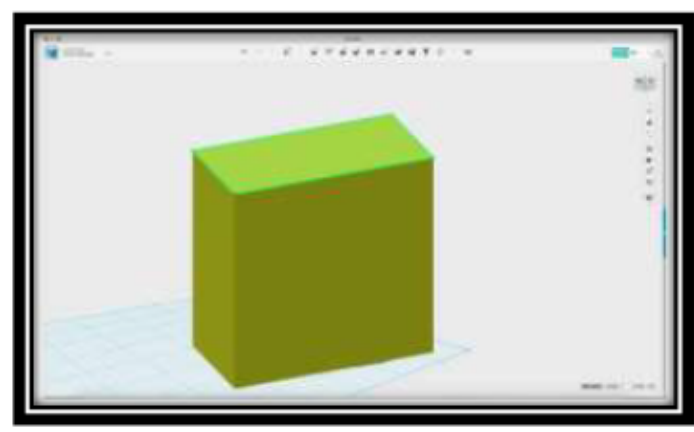

Figure 7: The modified primitive 


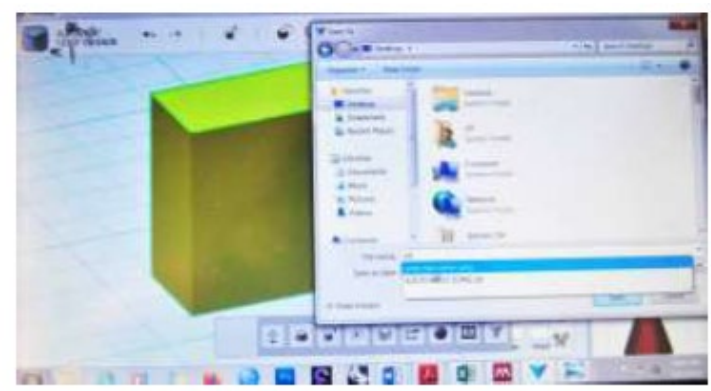

Figure 8: Snap shot of the generated package form saved for further design

The generated package form is opened in CorelDraw X5 for further design. There is no capability of using Autodesk 123D Design for pattern creation; hence, CorelDraw X5 has been used for colour application.

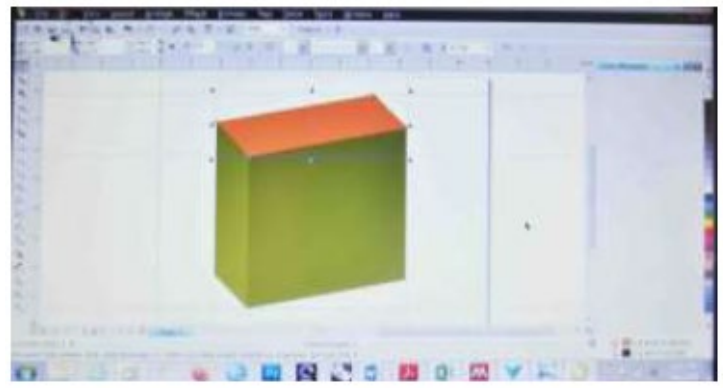

Figure 9: Application of orange colour in CorelDraw $X 5$
An elementary software like Autodesk 123D Design would have been excellent if all the design processes can be completed without collaborating or transferring the carton to CorelDraw. Orange colour have been added in Figure 9. The colour of the top of the carton has been transformed to orange. The package design elements such as images, and captions are also included with the indigenous Zobo tea in CorelDraw X5. A rectangle filled with orange colour have been laid on the carton. Two more rectangles are also filled with yellow and placed on the box (carton).

All these have been done by putting perspective in to consideration. 'ZOBO' which is a generic Nigerian name for Roselle or hibiscus have been positioned in perspective aligned to the box. The text is in white colour (see Figure 10). Adobe Photoshop works with layers; present stage of the design would have been in layers in Photoshop. The text wrapping tools and other free editing tools in Adobe Photoshop have assisted the placing of the text and images. Meanwhile the onomastics for indigenous Zobo tea have been derived through linguistics techniques of word formation. This will be explained in successive pages of this paper (see Table 3 ).

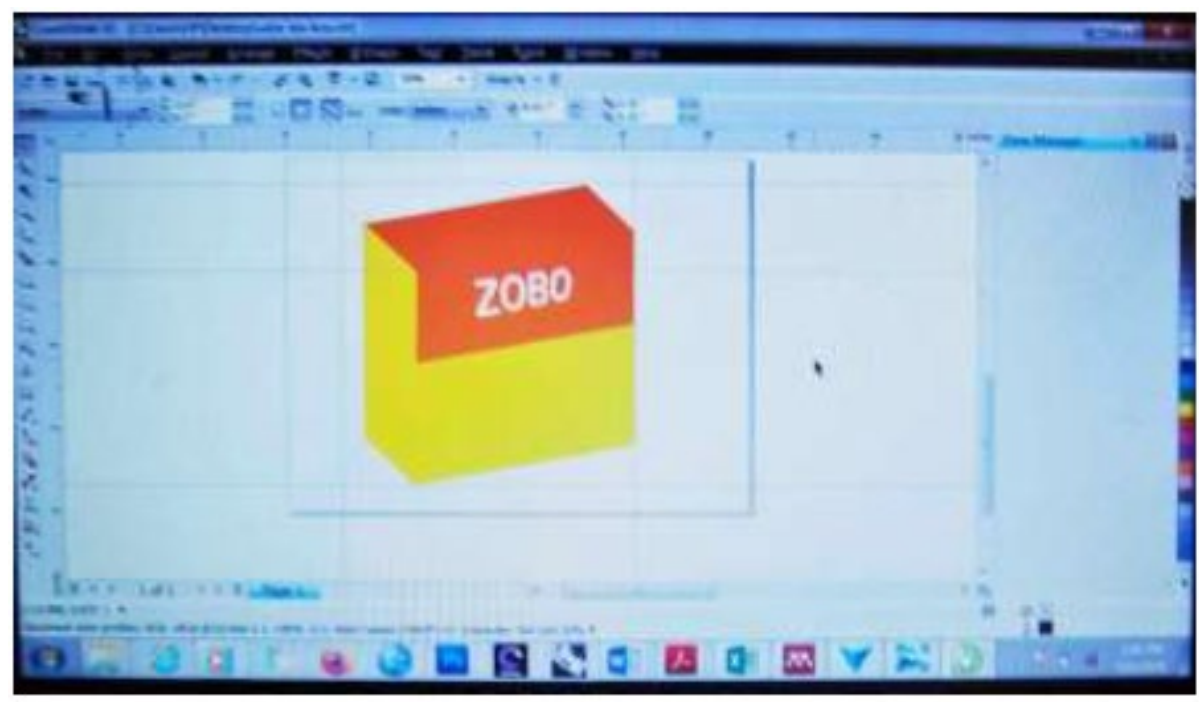

Figure 10: Yellow colour applied as well as the text are positioned in perspective 


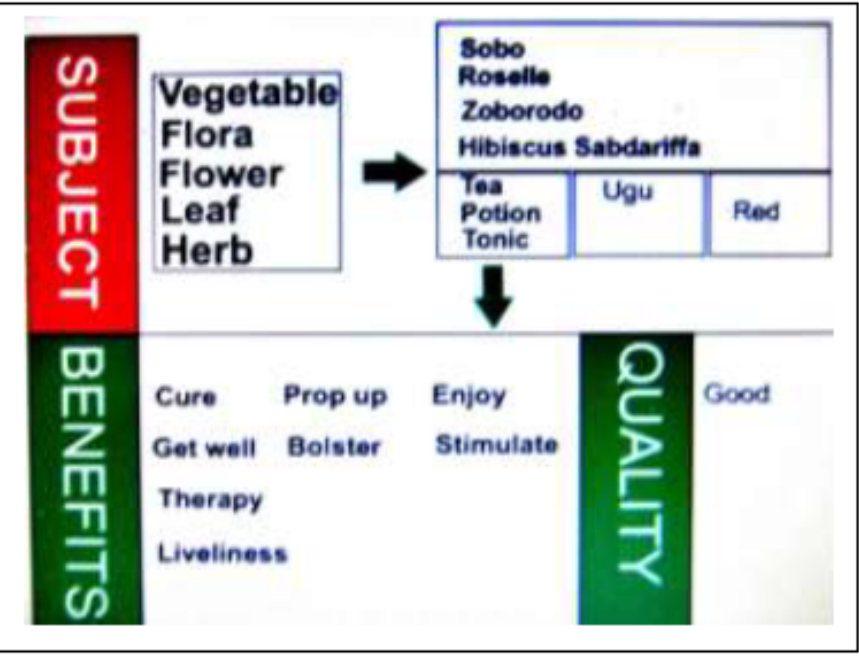

Figure 11: Semantic plan of typical indigenous Zobo tea

\subsection{Application of Zobo Tea Onomastics}

Tea is a non-alcoholic beverage which have the qualities of thirst quenching, stimulating, refreshing and nourishing. Tea plant originated in China; and the names are normally derived from shape of the leaf, its colour, scent, or flavor and other features (Chen, 1981). Naming of Tea has been problematic because there are different types of tea (Leo, 2020). In the naming of tea, the name of the cultivator, association of the appearance, description of the shape, production process, regional name, history, added aroma, and combination name may be applied (Leo, 2020).

Before applying linguistics techniques of word formation, the first approach is to look for words that would semantically fit the subject, quality and benefits of a typical tea. Bearing in mind that names are symbols of identities, present study identifies the Zobo tea as vegetable, shrub, flora, flower, leaf or herbs. This indigenous tea is present in almost everywhere, hence critics might oppose the word 'indigenous' as used in this paper. It is noteworthy that zobo is peculiar to Central and West Africa. It has been presented as indigenous in this paper because it has unique names in various locations and they are locally produced in Africa. Perhaps, present industries just began industrial production of the Zobo tea but it is not yet trendy in Africa. In Ghana, it is called Zobolo; Agua de Jamaica in Jamaica, and Bissap in Senegal. Roselle,
Florida Cranberry, Red sorrel, Jamaica sorrel and lots more in other parts of the world.

The Zobo tea is an indigenous tea called zobo (zoborodo) in the Hausa language. It is an edible plant called Hibiscus sabdariffa; it can also be called Roselle. In terms of the subject being studied, it can be tea, portion of drink, or tonic. The colour is reddish; hence, red can be another semantic association. The word 'Ugu' is an indigenous name for vegetable (here, it is arbitrary because it does not relate to the subject but it can be useful in the naming process). In terms of product benefits or quality, Zobo is refreshing, therapeutic, curative, and stimulating; hence the following words were discovered to be semantically similar to Zobo tea; namely, 'cure', 'get well', 'therapy', 'liveliness', 'prop up', 'bolster', 'enjoy', 'stimulate' and 'good' quality. The aforementioned explanation for brainstorming words fit for indigenous zobo tea can be seen in Figure 11. The subject is what we are naming; that is the Zobo tea. It can still be traced to the groups of vegetables, flora/flower, leaf, herbs and to mention a few. Thinking out side the box is necessary; so, arbitrary names related and unrelated are adopted. The benefits of the Zobo tea in terms of cure, getting well, therapy, liveliness, refreshingness, enjoyment, stimulation and to mention a few are put into consideration. 
The quality of the Zobo tea are put in to consideration. All these semantically generated words are used in the linguistic word derivation by using various techniques such as reduction, addition, direct burrowing, synonyms, compounding, semantic association, replacement techniques, eponyms, re-arrangements and to mention a few (see Table 3) .

From the study of Oluyemi and Oladumiye, alphanumeric, descriptive, eponyms, fanciful, generic, homonyms, toponyms, and suggestive names are the common onomastics for the branding of tea (Oluyemi, \& Oladumiye, 2020). Hence, present study, derives names for indigenous Zobo tea by building on the body of knowledge gained from the aforementioned study. Table 3 shows the derived names for the indigenous Zobo tea which consists of six generic, five suggestive, four descriptive, three homonym, two eponym and two fanciful onomastics. The total number of the derived names for the indigenous Zobo tea is all together 22.

Generic names are household names or those that are well known either by everybody or some set of people. Examples of these names may also be derived easily by reduction, addition, direct borrowing from other languages and the use of synonyms.

The reduction techniques for obtaining the name ' $Z o b o$ ' involves the removal of the suffix 'rodo' from the word 'Zoborodo'. Also, 'Hibiscus' was derived by removing the specie name 'sabdariffa' from 'Hibiscus Sabdariffa'. Likewise, when the genus name' Hibiscus' is removed, the name 'sabdariffa' was formed for the indigenous tea. In the botanical of Hibiscus, 'sabdariffa' is used as the name of the specie. The addition of suffix '-al' to 'Herb' obtained the word 'Herbal'. 'Roselle' is

Table 3: Derived names for the indigenous zobo tea

\begin{tabular}{|c|c|c|}
\hline Derived Names for Zobo Tea & Onomastics & Techniques \\
\hline Zobo & Generic & Reduction: zoborodo - zobo \\
\hline Hibiscus & Generic & Reduction: hibiscus sabdariffa - sabdariffa \\
\hline Herbal & Generic & addition of suffix: herb +- al \\
\hline Zoborodo & Generic & Direct Borrowing from Hausa language \\
\hline Roselle & Generic & Synonym of 'hibiscus' \\
\hline Sabdariffa & Generic & Reduction: hibiscus sabdariffa - hibiscus \\
\hline Ogood & Suggestive & $U g u+\operatorname{good}=$ ugood $=$ ogood \\
\hline Leaf Cure & Suggestive & Compounding: leaf + cure \\
\hline Tonic Cure & Suggestive & Compounding: tonic + cure \\
\hline Tonicare & Suggestive & Reduction: tonic - care \\
\hline Enjoyz & Suggestive & addition of suffix: enjoy $+\mathrm{s}=$ enjoys $=$ enjoyz \\
\hline Therapist & Descriptive & addition of suffix: therapy+ist $=$ therapist \\
\hline Red Flower & Descriptive & Compounding: red + flower $=$ red flower \\
\hline Prop Up & Descriptive & Semantic association \\
\hline Get Well & Descriptive & Semantic association \\
\hline Zoboh! & Homonym & Addition of Suffix: $z o b o+o h !=z o b o h !$ \\
\hline Sorboz & Homonym & Replacement Techniques: sorbose $=$ sorboz \\
\hline Oh! Dun & Homonym & Borrowing from Yoruba: $o d u n=o h !$ Dun \\
\hline Mrs. Roselle & Eponym & Addition of Title: Mrs + Roselle $=$ Mrs Roselle \\
\hline Dr. Therapy & Eponym & Addition of Title: $\mathrm{Dr}+$ Therapy $=\mathrm{Dr}$. Therapy \\
\hline Nipton & Fanciful & Re-arrangement: potion $=$ nipton \\
\hline Herbolster & Fanciful & Reduction Techniques: Herb + bolster \\
\hline
\end{tabular}


a synonymous word for 'Hibiscus'.

Suggestive name indirectly describes a product. 'Ogood' suggests the quality of the tea (.i.e. good tea). This depends on the mental schemata of the intending consumers. Compounding of 'leaf' and 'cure' as well as 'tonic' and 'cure' derived the name 'Leaf Cure' and 'Tonic Cure' respectively. 'Tonicare' was obtained through reduction while 'Enjoyz' was obtained through addition of suffix ' $z$ '. Descriptive names directly describe a product. The addition of suffix, compounding, and semantic association are used for the indigenous tea onomastics. 'Therapist' was derived from the addition of 'therapy' to the suffix 'ist'. 'Red Flower' was derived through compounding of 'Red' and 'Flower'. Semantic association was adopted for deriving 'Prop Up' and 'Get Well' as name for the indigenous zobo tea.

Homonyms are either homograph or homophone. Based on the onomastics for indigenous zobo tea, addition of suffix, replacement techniques, and borrowing from indigenous languages have been adopted. 'Zoboh!' is derived from the addition of ' $Z o b o$ ' and 'Oh!' while 'Sorboz' was derived through replacement techniques. 'Oh! Dun' was derived from borrowing from the Yoruba language (Nigerian language) the word ' $O$ dun'.

Eponym personifies the product as the name of a person. Addition of title have been adopted. 'Mr Roselle' and 'Dr Therapy' are derived from the addition of title 'Mr.' and 'Dr.' to the word 'Roselle' and 'Therapy' respectively. Fanciful names are coined names formed to represent the product. Re-arrangement technique is used for deriving 'Nipton' by transforming 'Portion' to 'Nipton'. By using reduction technique, 'Herbolster' is formed by removing the double ' $b$ ' in the combination of 'Herb' and 'bolster'.
Also, a modified Delphi technique is applied to evaluate the conceptual prototype package design allied with the zobo tea indigenous onomastics. This means that the derived names for the indigenous zobo tea are designed on the conceptual package design prototype and then evaluated. Based on modified Delphi model, five Delphi participants are purposively selected. These participants are anonymous and they have a good understanding of product package design and onomatics.

Likert scale of 5 to 1 is adopted for the evaluation of the conceptual prototype package design allied with the zobo tea indigenous onomastics, where $5=$ Excellent, $4=$ Good, 3 =fair, 2 = poor, 1 = bad. The anonymous participants are to rate the conceptual prototype package design allied with the zobo tea indigenous onomastics based on the variables shown in table 4. There are 14 variables in all (V1 to V14). The result of the evaluation is then statistically presented by using bar chart.

A graphically appealing product name is considered to be well copy fitted to the packaged design in terms of aesthetics, typography, and layout orientation (arrangement). Also, the length of word could assist the aesthetics and simplicity of the design. Easy understanding and pronunciation of the word have been considered by prior researches to be important for the friendliness of the product brand. The distinctiveness of the word in terms of been easy to remember and entirely different from any other names are necessary while designing new brands. Product names that are attention grabbing and advertise-able could be persuasive. Also, the aforementioned assist the trademark-ability of the brand. According to prior researches such words are far from common nouns (generic onomastics). 
Table 4: Example of variable (VAR) for the evaluation of the conceptual prototype package design allied with the zobo tea indigenous onomastics

\begin{tabular}{|c|c|c|c|c|c|c|}
\hline VAR & STATEMENTS & Excellent & Good & Fair & Poor & Bad \\
\hline V1 & The product name is graphically appealing & & & & & \\
\hline $\mathrm{V} 2$ & The length of word is of appropriate length & & & & & \\
\hline V3 & Easy understanding & & & & & \\
\hline V4 & Easy pronunciation & & & & & \\
\hline V5 & Distinctive enough to be remembered & & & & & \\
\hline V6 & $\begin{array}{l}\text { Distinctive enough to be differentiated from other similar } \\
\text { products }\end{array}$ & & & & & \\
\hline V7 & The product name is attention grabbing & & & & & \\
\hline V8 & The product name is advertise-able & & & & & \\
\hline V9 & The product name is persuasive & & & & & \\
\hline V10 & The product name is capable of serving as a trademark & & & & & \\
\hline V11 & The product name is free form negative connotation & & & & & \\
\hline V12 & The product name fit the package design type (i.e. shape) & & & & & \\
\hline V13 & It is capable of arousing consumers' emotion & & & & & \\
\hline V14 & It is modern/contemporary - (not too local) & & & & & \\
\hline
\end{tabular}

\section{Result and Discussion}

Based on the findings of this study, some hypotheses are generated. This involves the typicality of product onomastics as regards the adopted non-word/ word derivation techniques. Recall that the notion of this study also includes the concept of aligning product attributes to the concept of typicality/congruity (.i.e. standard or what is used predominately; they are attributes that is believed consumers will be most confident of its attributes). Based on the relationship between the typical onomastics assumed for Zobo tea (namely, generic, suggestive, descriptive, homonym, eponym, and fanciful) and the linguistics techniques (.i.e. non-word/word formation techniques) present study notices the hypothesis that there is freedom for using any linguistics techniques to designate product onomatics despite product typicality consideration.

\subsection{Inference from Derivation of Names for Indigenous Zobo Tea by making use of linguistics Techniques}

Figure 12 displays a stacked area chart highlighting the trend of the possibility of Zobo tea product onomastics to becoming generic. The blue area represents generic onomastics; it has the highest popularity/typicality. In Figure 12, generic onomastics are not derivatives of compounding, semantic association, replacement, addition of suffix, and rearrangement techniques. Following the hypothesis, can these five techniques be used for generic onomastics and still remain typical for Zobo tea? Or generic onomastics typical for Zobo tea should be designated by using reduction, addition of suffix, direct borrowing, and synonyms only? 


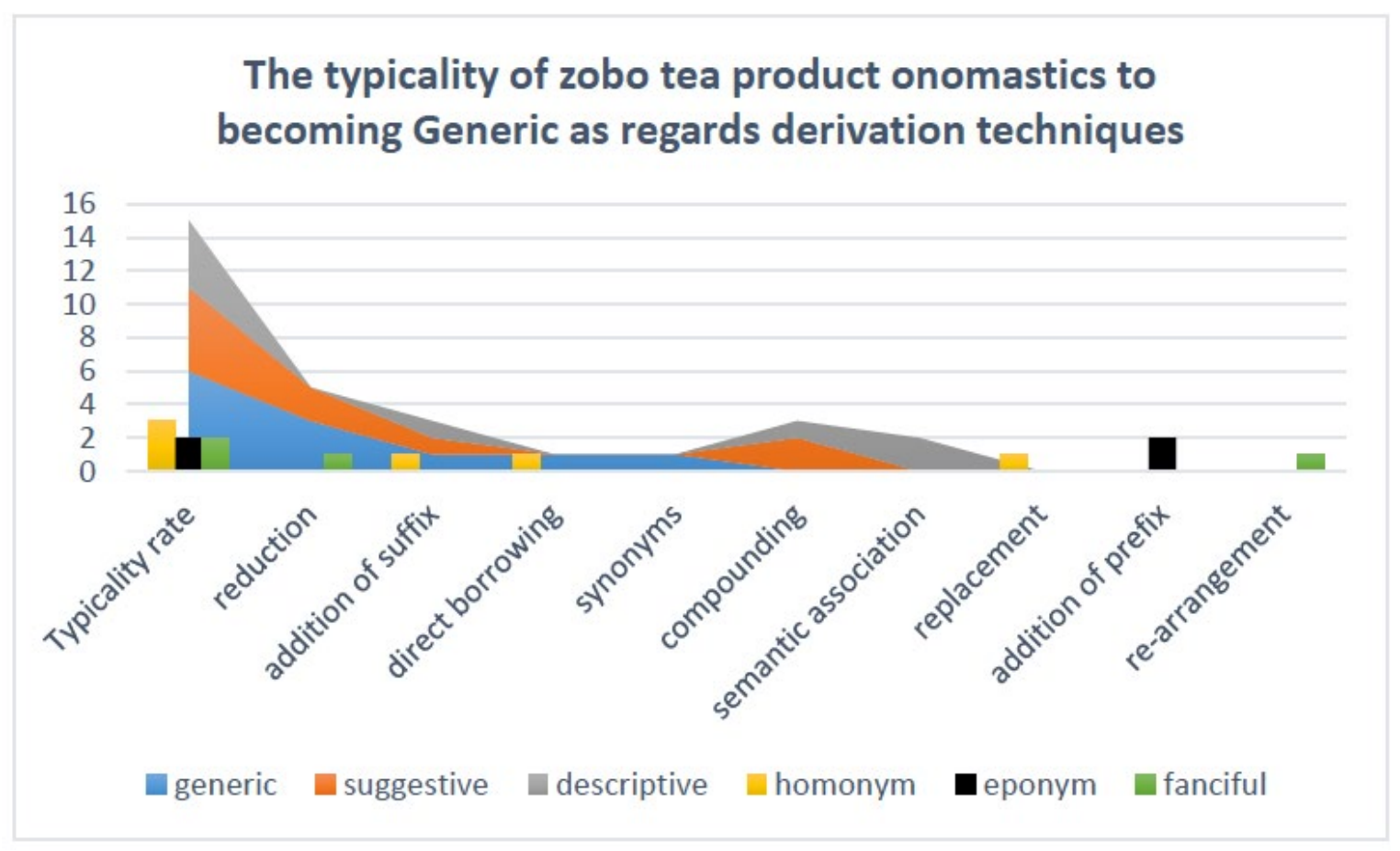

Figure 12: the trend of the possibility of zobo tea product onomastics to becoming generic

So, it covers more area from reduction to synonyms; can it be that the use of techniques ranging from compounding to re-arrangement will make generic onomastics far from a dictionary word (.i.e. less generic)? It can be inferred that most of the categories are derived from a generic terms. For instance to derived names for Zobo tea different from the already derived ones in Table 3, Dr $+Z o b o={ }^{\prime} D r$ Zobo'; Nutri + zobo = 'Nutrizobo' (.i.e. addition of prefix) will generate eponym and suggestive names respectively; Zobo rearranged as 'Ozbo', 'Bobz', 'Oobz', and 'Zoob' will generate fanciful names or non-word irrelevant names. It can be opined that addition of prefix and re-arrangement will not lead to generic onomastics. Research and collection of various generic terms are the beginning of naming process for a Zobo tea. These terms can then be transformed to other onomastics such as suggestive, descriptive, fanciful names and to mention a few.

Suggestive onomastics are not derivatives of synonyms, direct borrowing, semantic association, replacement, addition of suffix, and re-arrangement techniques in figure 12 .
Following the hypothesis, can these six techniques be used for suggestive onomastics and still remain typical for Zobo tea? Or suggestive onomastics typical for Zobo tea should be designated by using compounding, reduction, and addition of suffix only? In Figure 12, the orange area represents suggestive onomastics; it is the next in popularity/typicality after generic onomastics. So, it covers area from reduction to compounding; can it be that the use of techniques ranging from semantic association to re-arrangement will make suggestive onomastics less suggestive? For instance, Prop $U p=G o+$ Higher $=$ GoHigher (.i.e. semantic association/compounding); 'Zobo' + 'Bissap' $=$ 'Zobossap' (.i.e. direct borrowing from Senegal with addition/blending technique). Direct burrowing will still make the product generic except when it is changed to another name by the use of other derivation techniques (i.e. 'Bissap' changed to 'Zobossap'). The Zobo at the prefix will be an anchorage for suggesting 'Zobossap' to be a Zobo drink. 'Zobossap' is a non-word that can sound relevant to Zobo drink. The use of synonyms .i.e. Hibiscus $=$ Sorrel $=$ Roselle $=$ Zobo $=$ 
Zoborodo $=$ Zobolo and to mention a few will still make it generic. There is need to change them to another name by the use of other derivation techniques.

It can be inferred that combination of various derivation techniques are needed to a form typical onomastics far from genericity for a Zobo tea. In Figure 12, the grey area represents descriptive onomastics; it is the next in popularity/typicality after suggestive onomastics. Reduction, direct borrowing, synonyms, replacement, addition of prefix and rearrangement are not used for the derivation of descriptive onomastics as seen in Figure 1 Synonyms should be able to derive descriptive names; for instance, Rich tea $=$ Fine tea $=$ Fruitful $=$ Prolific $=$ Bountiful are descriptive. It can be inferred that not all derivation methods can be used to obtain descriptive names. Reduction, direct borrowing, replacement, re-arrangement, and addition of prefix will rather generate suggestive than descriptive onomastics. The yellow area represents homonym; it is the next in popularity/typicality after descriptive onomastics as seen in Figure 12. Reduction, synonyms, compounding, replacement, semantic association, and addition of prefix are not used for the derivation of descriptive onomastics as seen in Figure 12. Direct borrowing, replacement, re-arrangement, and addition of suffix are used for deriving homonyms. Addition of prefix with the use of direct borrowing from other languages like 'Mun', 'Sha', 'Nuo' means 'drink' in Yoruba, Hausa and Igbo respectively should be able to form homonym; however, it depends on culture/tribe. 'Munzobo' = 'Mun' + 'Zobo' (Munzobo is a name of person in a particular tribe. Accidentally 'Munzobo' drink will be eponym to someone in such region whereas it was formed as homonym in another region). In English language translation, 'Munzobo' means 'Drinkzobo'; 'Shazobo' = 'Sha' + 'Zobo'; 'Nuozobo' = 'Nuo' + 'Zobo' ('Shazobo' and 'Nuozobo' also mean 'Drinkzobo'). The traditional language of a particular tribe will determine if a word is homonym or not. Based on global consideration, what is homonym in Nigeria may not be homonym in another country. It may be meaningless to another human being. The most important criteria in such situation is that it must not have negative connotation. In Figure 12, addition of title is used for deriving eponym. The title added is still a form of prefix. Earlier, eponym is formed accidently from the incorporation of direct borrowing and the addition of prefix. It can be inferred that it is more possible for addition of suffix to form homonym while it will be more possible for addition of prefix to form eponym; however, it may be still homonym to somebody from a particular tribe.

The black area represents eponym; it is the next in popularity/typicality after homonym as seen in Figure 12 while the green area represents fanciful onomastics; it is the next in popularity/typicality after eponym onomastics. Fanciful names are derived through the use of re-arrangement and reduction techniques in Figure 12. This is does not mean that other derivation techniques cannot be used. For instance clipping and reduction can be used. Zobo can be reduced to ' $Z o b$ ' (.i.e. reduction), 'Zobo' + 'late' = 'Zobolate', 'Zobo' + rich = 'Zoborich', 'Nutri' + 'Zobo' = 'Nutrizobo' (.i.e. addition of suffix and addition of prefix respectively), 'Nutrizobo' - 'triobo' = 'Nuz', 'Zoborich' - bo = 'Zoch' (.i.e. clipping). There is need for the combination of derivation techniques to form fanciful names. Suggestive names are formed when the addition of suffix and prefix are used. Further use of clipping transformed the suggestive names to fanciful names .i.e. 'Nuz' and 'Zoch'. Both can still be further transformed through replacement technique to 'Nus' and 'Soch'.

Product onomastics for a Zobo tea or other products cannot be done without proper research; the task is highly demanding. This is similar to the declaration of Kohli \& LaBahn, (1997) that the process involved in product naming can take months or years to complete. Some key steps include specifying the objectives of the branding, developing the product name itself, evaluating names through target market testing and focus groups, choosing a final product name, and finally 


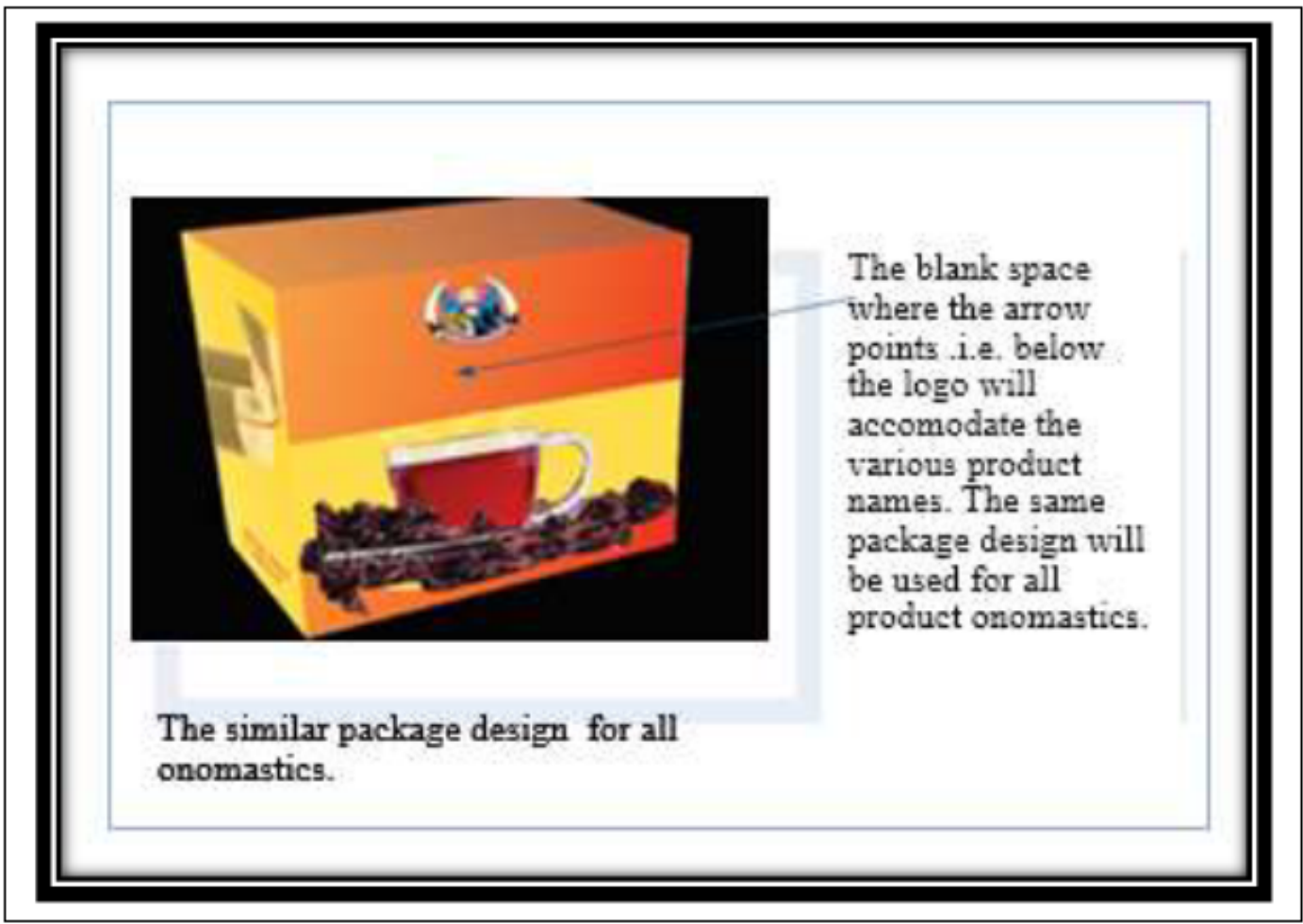

Figure 13: the similar package design and the blank space for the derived Zobo names

identifying it as a trademark for protection. The use of a relevant generic term either at the prefix or suffix will be an anchorage for suggesting a Zobo drink. Research and collection of various generic terms are the beginning of product onomastics for a Zobo tea. It can be opined that addition of prefix and re-arrangement will not lead to generic onomastics; however, most of the onomastics categories are derived from a generic terms. These terms can be transformed to other onomastics such as suggestive, descriptive, fanciful names and to mention a few.

It can be inferred that it is more possible for addition of suffix to form homonym while it will be more possible for addition of prefix to form eponym; however, it may be still homonym to somebody from a particular tribe. The traditional language of a particular tribe will determine if a word is homonym or not. Based on global consideration, what is homonym in Nigeria may not be homonym in another country. It may be meaningless to another human being. The most important criteria in such situation is that it must not have negative connotation. Notably, the combination of various derivation techniques are needed to a form typical onomastics far from genericity for a Zobo tea.

\subsection{Evaluation of the Conceptual Package Design for Zobo Tea Allied with Product Onomastics through the Delphi Techniques}

It is worthy of note that the package designs were created in similar colour, typography, image logo and other elements are also the same because of constant condition (see Figure 13). Only the names will be changed but other design variables will be similar. The variables considered are restricted to the product name and typical package design. This has been done in order to avoid noise or extraneous elements in the findings. Similar studies by Pamungkas, Shrum, Keller, Schmidt, Malik and Olateju to mention a few are purely linguistic based (Pamungkas, \& Abdulah, (2017), Shrum, Lowrey, Luna, Lerman \& Liu (2012), Keller (2013), Schmidt, (2011), Malik (2015), and Olateju, Akande \& Akinwale, 2009) 


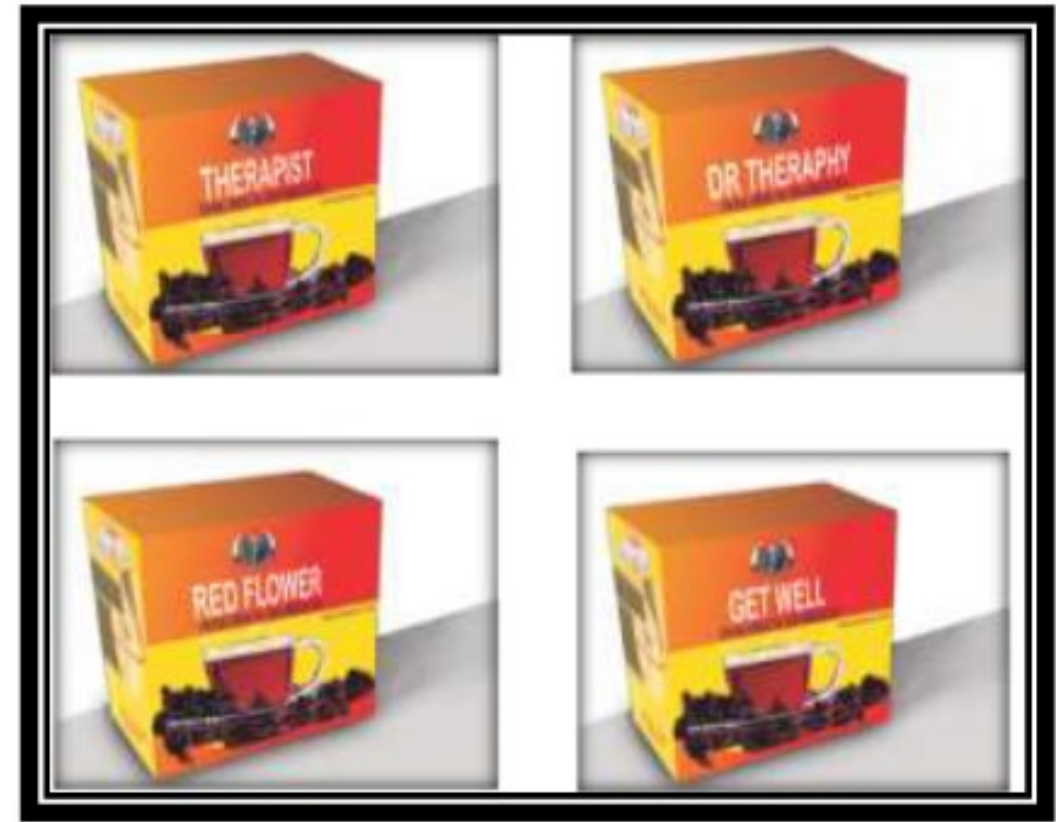

Figure 14: conceptual prototype package design allied with the zobo tea indigenous onomastics i.e. Therapist (Eponym), Red Flower (Descriptive), Dr Therapy (Eponym), Get Well (Descriptive)
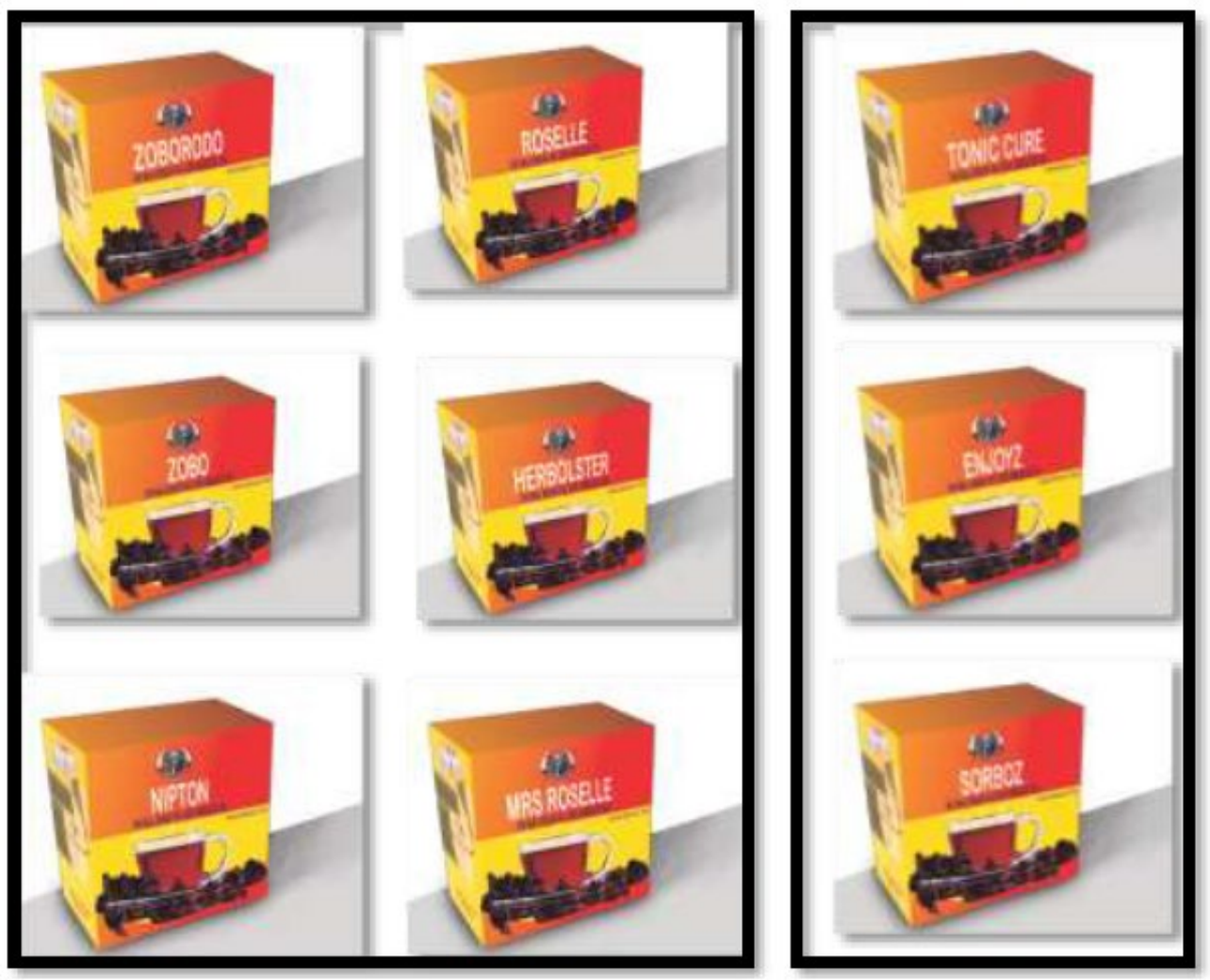

Figure 15: Conceptual prototype package design allied with the zobo tea indigenous onomastics.i.e. Zoborodo (Generic), Roselle (Generic), Tonic Cure (Suggestive), Zobo (Generic),Herbolster (Fanciful), Enjoyz (Suggestive), Nipton (Fanciful), Mrs Roselle (Eponym), and Sorboz (Homonym) 

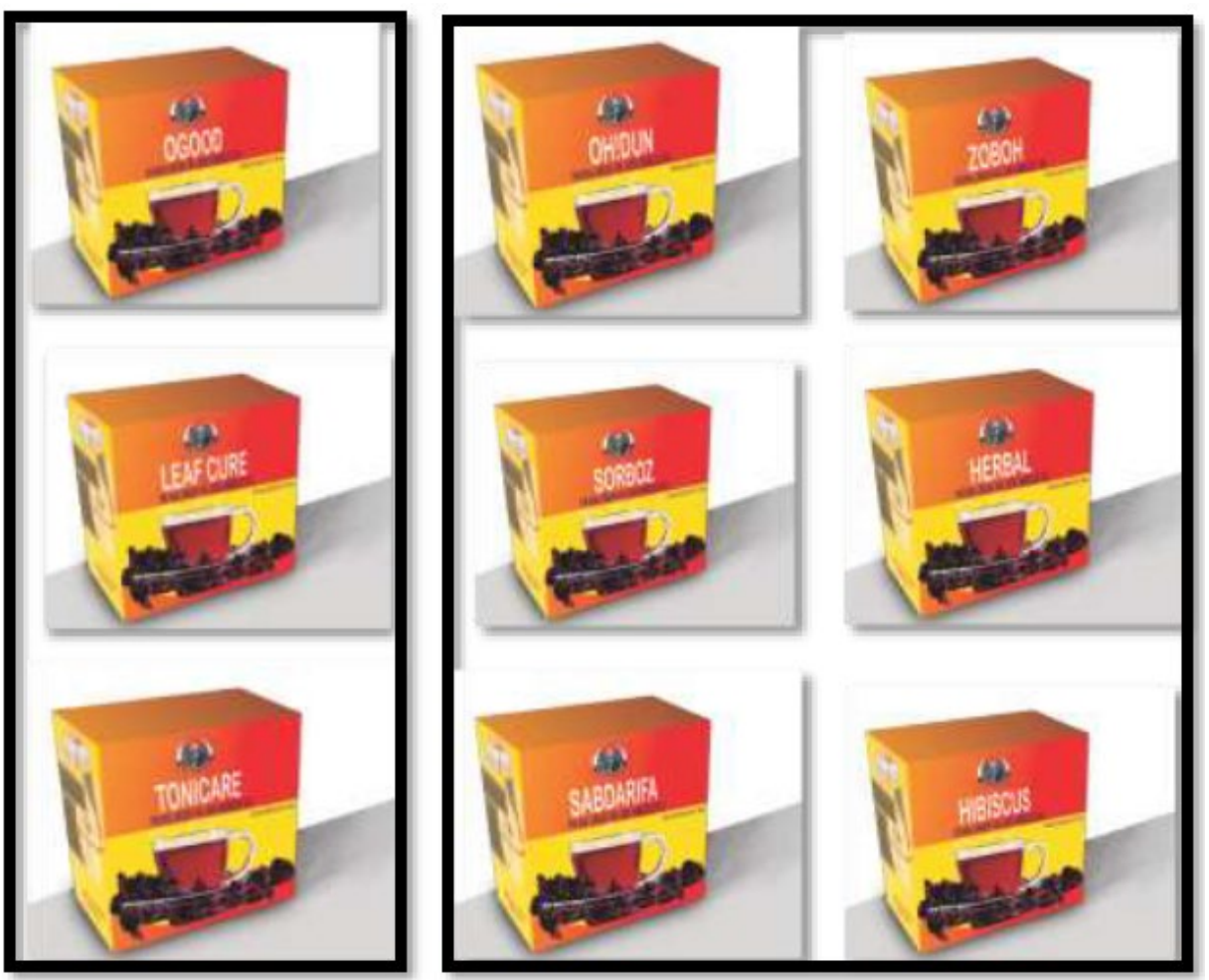

Figure 16: Conceptual prototype package design allied with the Zobo tea indigenous onomastics.i.e. Ogood (Suggestive), O!Dun (Homonym), Zoboh (Homonym), Leaf Cure (Suggestive), Sorboz (Homonym), Herbal (Generic), Tonicare (Suggestive), Saabdariffa (Generic), and Hibiscus (Generic)

They only laid emphases on the techniques of naming; hence present study creates conceptual prototype package design allied with the Zobo tea indigenous onomastics by adopting Delphi techniques for the evaluation of the 22 conceptual Zobo tea package design. The aspect of graphic appeal and the fitness of product name to package shape are incorporated in to the evaluation because of the product name are evaluated in the environment of the Zobo tea package design. The product names are not evaluated in isolation from product package design (i.e. salient salesman). This makes the present exploratory study different from prior research by Pamungkas, Shrum, Keller, Schmidt, Malik and Olateju. Therefore, a blend of marketing, legal, linguistics and design criteria are used for the evaluation of the conceptual Zobo tea package designs in Figure 14 to Figure 16. Figure 14 to Figure 16 show the conceptual prototype package design allied with the zobo tea indigenous onomastics.
Through Delphi techniques, 22 derived names for indigenous zobo tea which are six generic, five suggestive, four descriptive, three homonym, two eponym and two fanciful onomastics are evaluated by the anonymous participants and the results showed that homonym is the most suitable for the conceptual prototype package design allied with the zobo tea indigenous (see Figure 17 for the bar chart showing the result of evaluation based on Delphi techniques). Figure 18 shows the homonym (i.e. OH!DUN) designated and used as label for the indigenous Zobo tea carton (package design). This has been selected to be the most suitable among the 22 derived names for the conceptual prototype package design allied with the Zobo tea indigenous. It is rank as the most appropriate because it has overall mean score of 3.8, which can be approximated to 
4.0. Point 4 on the likert scale means OH!DUN is good as the label for the name of a typical Zobo tea conceptual package design. On the 5 point Likert scale, it assumed that the selected name is excellent while point 4 is good for the labelling of indigenous tea. It is a surprising

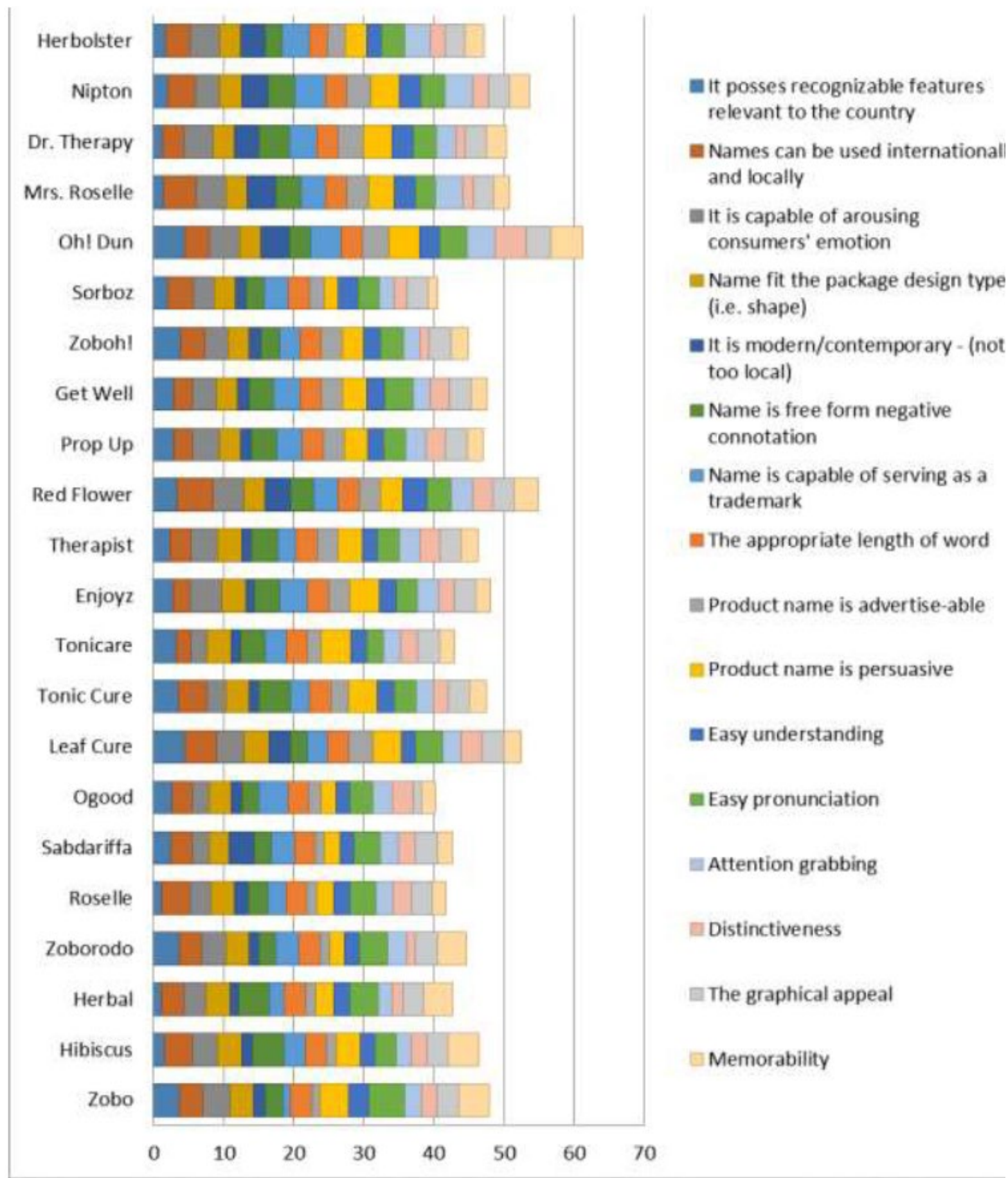

Figure 17: The bar chart showing the result of evaluation based on Delphi techniques 
that an excellent product onomastics is not discovered in the study but a good product onomastics.

The evaluation criteria used for the evaluation of the conceptual prototype package design allied with the Zobo tea indigenous onomastics showed that ' $\mathrm{OH}$ ! DUN' is a name which has recognizable features relevant to indigenous location (.i.e. Nigeria). The Likert scale of this variable is 4.5 (.i.e. excellent). Due to globalization, the evaluation of the name ' $\mathrm{OH}$ ! DUN' has a Likert scale of 3.5 (.i.e. good) which means it can be international and locally used. The name is capable of arousing consumers' emotion on the Likert scale of 4.4. However, the name fairly fits the shape of the package design with a Likertscale of 3 . Probably because of the shortness of the length. It is also capable of serving as a trademark on scale of 4.4. It also has the following good characteristics, namely: memorability (4.5), graphic appeal (3.5), distinctiveness (4.5), attention grabbing (4.0), understanding (3), pronunciation (3.8), and persuasiveness (4.3). The mean rating of the evaluation of the name ' $\mathrm{OH}$ ! DUN' as a homonym onomastics is 3.8 . Hence, homonym is preferable as Zobo tea indigenous onomastics among others such as descriptive, eponyms, fanciful, generic, and suggestive names.

\section{Summary and Conclusion}

Product onomastics will enhance branding and development of the indigenous product especially zobo tea. As part of the contribution to knowledge, this study identifies homonym as a naming styles. This is not enough to prove that they are the best fitting naming styles for indigenous zobo tea. Various derivation techniques can be combined so as to get befitting names that will serve as a good trademark and as well as persuasive to consumers in the international market. More researches are needed before an excellent product onomastics can be designated for an indigenous product. A new economy that will benefit designers positively in the aspect of adequate digital amenities is necessary for better product package innovation and development in Nigeria, especially for the

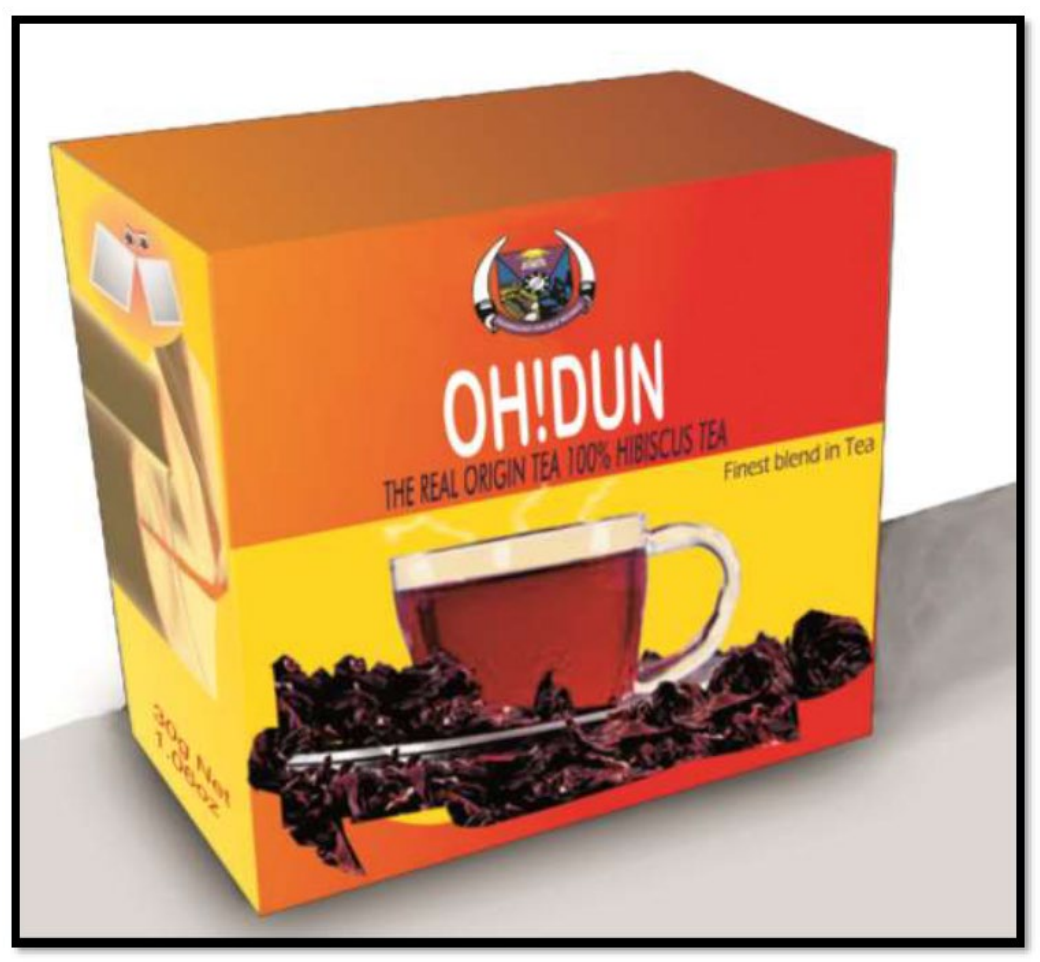

Figure 18: The desirable product onomastics (homonym) for indigenous Zobo tea conceptual package design 
university students studying design related courses. Both elementary (i.e. easy to use CAD software) and advanced CAD software should be made available for both students and lectures that specialize in design related profession in developing countries. CAD software programmer and industry should put the third-world countries into consideration while designing CAD software by making the software to be compatible with less sophisticated computer as well. Graphic design should not be limited to pictures, images, layout, typography, and other visual aspect of package design. Present study has shown an example of creative ways graphic designers can harness the theories of other disciplines to a design studio practice. There is need for further study even in a similar way to prove right or wrong the hypothesis discovered in the findings of this exploratory study. As this study only discovered homonym to be good for Zobo tea package design, proper research will still establish the excellent product onomastics to be the most appropriate. Hence, research on the choice of appropriate name for a particular product should be a contemporary research area because of its latent effectiveness and significance for successful package design which needs to be unfolded further. This will go a long way in improving the present situation of indigenous products and graphic design in terms of branding and product development. The conceptual prototype package design allied with the Zobo tea indigenous onomastics is assumed to be visually pleasing, attractive and good example for our indigenous products. Accordingly, graphic design training institution should encourage the harnessing of multidisciplinary perspective with the graphic design profession because of clients' high expectancy and the need to expand the scope of graphic design for the purpose of job opportunities for future designers.

\section{Acknowledgement}

The corresponding author is especially indebted to Professor E.B Oladumuyi and Dr O.S Adelabu because the maturity of this exploratory study began under their tutelage and supervision in the Industrial Design
Department, Federal University of Technology Akure in Nigeria. Finally, the authors would like to thank the anonymous experts without whose cooperation this study could not have been possible. We also like to say Glory be to God.

\section{Conflict of Interest}

We declare that we have no conflict of interest.

\section{References}

Abushawali, M., Lim, Y. P., \& Bedu, A. R. (2013). The Impact of New Digital Media on Graphic Designer in Jordan. International Conference on Informatics and Creative Multimedia, 275-278.

http://doi.org/10.1109/ICICM.2013.34

Awe, F. F., Fagbemi, T. N., Ajibola, C. F., \& Badejo, A. A. (2012). The Antioxidant Capacity of Beverage Blends Made from Cocoa , Zobo and Ginger. International Journal of Biological, Biomolecular, Agricultural, Food and Biotechnological Engineering, 6(8),

626-630.

Barmaki, H., (2012). The Role of Design in Sustainable Consumption A Study on Sustainable Food Packaging. Istanbul Technical University. Graduate School of Science Engineering and Technology.

Blijlevens, J., Creusen, M. E. H., \& Schoormans, J. P. L. (2009). How Consumers Perceive Product Appearance: International Journal of Design, 3(3), 27-35.

Chan, A.K.K., \& Huang, Y.Y. (1997). Chinese brand naming: From general principles to specific rules. International Journal of Advertising, 16(4), 320-335.

Chen Chuan (1981). Tea Classification in Theory and Practice. Journal d'agriculture traditionnelle et de botanique appliquée, XXV111. 3-4

Collins Dictionary (2012). Conceptual Prototyping.https://www.collinsdictionary.com 
Keller, L., (2013). Strategic Brand Management: Building, Measuring, and Managing Brand Equity. Fourth Edi. Harlow UK: Pearson Education Limited,

Kohli, C., \& LaBahn, D.W. (1997). Observations: Creating effective brand names: a study of the naming process. Journal of Advertising Research, 37 .

Kirk, L. E. (2013). Visual Branding In Graphic Design. University of Southern Mississippi. Retrieved from

http://aquila.usm.edu/honors_theses,

Leo Kwan (2020). Naming of a tea. Retrieved online: www.teaguardian.com

Lertcheva, N., \& Aroonmanakun, W. (2011). Product Name Identification and Classification in Thai Economic News. In Proceedings of the 2011 Named Entities Workshop, IJCNLP. Chiang Mai, Thailand, 58-64

Lindstrom, M. (2001). Corporate branding and the web: A global/local challenge. Brand Management, 8 (4/5)

Malik, S. (2015). Linguistic Iconicity in Brand Names: Derivational Morphology Based Analysis. Pakistan Journal of Social Sciences (PJSS), 35(2), 799-810.

Marcel Danesi. (2013). What's in a brand name? A note on the onomastics of brand naming DOI:

https://doi.org/10.1179/002777311X13082331 190119 pages $175-185$ 59(3),

Najmuldeen, R. (2021). The Digital Divide And Its Implications For Graphic Designers. BABIR International Journal for Human Sciences, 3(1), 27-33.

Ogunsote, O. O., Prucnal-Ogunsote, B., \& Umaru, N. A. (2006): Computer Aided Architectural Presentation ( CAAP) Software, (October),

Olateju, M., Akande, \& Akinwale (2009). Morphological Processes in Product Naming
By Trado-medical Practitioners in Nigeria,

Oladumiye, Oluyemi and Adelabu (2018).The Visual Typicality of Non-Alcoholic Beverage (NAB) Package Forms in Akure, Nigeria; Arts and Design Studies, Vol.66, 1- 15.

Oluyemi, A. S., and Oladumiye, E. B (2020). General Appraisal of the Nomenclature of Non-Alcoholic Beverages (NAB) Brands. SCHOLEDGE International Journal of Multidisciplinary \& Allied Studies 7(1), 1-13, Retrieved from

https://link.thescholedge.org/1207www.theSC HOLEDGE.org

Pamungkas, K., \& Abdulah, R (2017). Linguistics-Based Pharmaceutical Product Naming Methods: A Morphological Study On Over the Counter Medicine Products In Indonesia.

Schmidt, D. (2011). Psycholinguistic Investigations of Brand Names via Word Recognition and Memory Experiments. University of Windsor, Retrieved from http://scholar.uwindsor.ca/etd

Shrum, L.J., Lowrey, T.M., Luna, D., Lerman, D.B. \& Liu, M. (2012). "Sound symbolism effects across languages: Implications for global brand names," International Journal of Research in Marketing, Vol. 29, 275-279.

Yang, W. (2018). Packaging design development for Taiwanese souvenirs. Iowa State University. 